\title{
A SIMPLE MEDIUM FOR THE RAPID DETECTION OF SALMONELLA-LIKE PARACOLON ORGANISMS
}

\author{
BY \\ G. H. LOWE AND J. H. EVANS \\ From the Public Health Laboratory, Newport, Mon.
}

(RECEIVED FOR PUBLICATION JANUARY 14, 1957)

Routine investigation of faeces frequently yields paracolon bacilli some of which after 24 hours' incubation produce the biochemical reactions of the salmonella group. Usually these "salmonellalike" paracolon bacilli can be distinguished from salmonellae by negative serological findings and, later, by the delayed fermentation of lactose, sucrose, or salicin. Occasionally, however, they may contain a specific salmonella antigen, or antigens, and although they usually fail to agglutinate with the appropriate antiserum to full titre a strong slide agglutination reaction may be obtained. As most presumptive reports of salmonella isolations are based on slide agglutination results coupled with favourable biochemical reactions, the difficulties presented by organisms of this type are appreciable.

A considerable number of salmonella-like paracolon organisms isolated in this laboratory during the past five years have given the following biochemical reactions after 24 hours' incubation: acid and gas were produced from glucose, mannitol, maltose, and dulcitol but not from lactose, sucrose, or salicin; $\mathrm{H}_{2} \mathrm{~S}$ was produced, indole and urease were not formed. After two to five days' incubation all strains fermented lactose and some also fermented salicin. Sucrose was not fermented even after 21 days' incubation. It would appear, therefore, that delayed fermentation of lactose is characteristic of such paracolon bacilli, and a medium enabling these organisms to ferment lactose within 24 hours would obviate the usual delay in distinguishing them from the salmonellae.

Massini (1907) demonstrated that delayed fermentation of lactose by Bacterium coli mutabile was due to the slow production of rapid lactosefermenting mutant cells. These mutant cells appeared to retain this characteristic indefinitely. Many workers investigating delayed fermentation of substrates by organisms of the coli-typhoiddysentery group have confirmed the findings of Massini. Lewis (1934), using a synthetic medium containing lactose as the sole carbon source, found that the lactose-fermenting mutants of a mutabile type of colon bacterium occurred at a constant frequency of approximately one lactose-fermenting cell to 100,000 non-lactose-fermenting cells, and that these mutants occurred spontaneously when grown on media not containing lactose. He also showed that unless $5 \%$ of lactose-fermenting mutant cells were present in a population, fermentation of $1 \%$ lactose peptone water would not occur within 24 hours. With this and other experimental evidence available, it appears that delayed fermentation of substrates by various organisms usually depends on the presence of sufficient rapidly fermenting mutant cells.

Kriebel (1934), investigating a number of latelactose-fermenting paracolon bacteria, found that fermentation occurred more rapidly in a medium containing $5 \%$ lactose than with greater or lesser amounts. Although the fermentation time of these organisms was shortened, a positive reaction was not obtained within 24 hours. Chilton and Fulton (1946) reported that $10 \%$ lactose agar slants heavily inoculated with slow lactosefermenting paracolon organisms did in some instances give evidence of fermentation within 24 hours. No explanation of these phenomena was offered, but the investigations Kriebel described suggested that further work along these lines was the method most likely to yield a medium of the type sought.

Fermentation Reactions of Culture E.C.8 in 1\% and $5 \%$ Lactose Peptone Media

Test Organism.-As the salmonella-like paracolon organisms isolated in this laboratory appeared to resemble each other closely, it was decided to make preliminary investigations on one strain of this type. The strain selected was obtained from the National Collection of Type Cultures, serial number 8827, and will be referred to throughout this paper as culture E.C.8. Biochemically this organism after 24 hours' incubation resembled a salmonella. Lactose and 
salicin were fermented after three days' incubation, and sucrose was not fermented after 21 days' incubation.

Control Organisms.-Strains of Salmonella typhimurium and Bact. coli type I were put up in parallel with all experiments to act as controls of the media.

Culture Media.-One batch of Evans' bacteriological peptone was used for all peptone media described. Liquid media containing lactose were sterilized by Seitz filtration. The lactose peptone agar was prepared by mixing equal amounts of filtered double-strength lactose peptone water and autoclaved molten aqueous agar containing neutral red as the indicator. The final $p \mathrm{H}$ of all media was 7.2.

Procedure-Colonies of culture E.C.8 grown on peptone agar were suspended in sterile distilled water, and a suitable dilution was made to give approximately 20,000 viable organisms per $0.02 \mathrm{ml}$. One standard drop $(0.02 \mathrm{ml}$.) of this suspension was inoculated or plated on to each of the following : (1) $5 \mathrm{ml}$. of $1 \%$ lactose $1 \%$ peptone water, plus Andrade's indicator; (2) $5 \mathrm{ml}$. of $5 \%$ lactose $1 \%$ peptone water, plus Andrade's indicator; (3) $1 \%$ lactose $1 \%$ peptone agar, plus neutral red indicator ; (4) $5 \%$ lactose $1 \%$ peptone agar, plus neutral red indicator.

The lactose peptone water tubes were plated daily on to $1 \%$ and $5 \%$ lactose peptone agar for the detection of lactose-fermenting mutant cells.

Results.-The results obtained with the lactose peptone liquid media are summarized in Table I. In the $1 \%$ lactose peptone water it is apparent

TABLE I

FERMENTATION AND PRODUCTION OF LACTOSE-FERMENTING MUTANTS OF CULTURE E.C.8 GROWN IN $1 \%$ AND 5\% LACTOSE PEPTONE WATER

\begin{tabular}{|c|c|c|c|c|c|}
\hline \multirow{2}{*}{ Medium } & \multirow{2}{*}{ Result } & \multicolumn{4}{|c|}{ No. of Days' Incubation } \\
\hline & & 1 & 2 & 3 & 4 \\
\hline $\begin{array}{l}\% \text { lactose } \\
\text { peptone } \\
\text { water } \\
5 \% \text { lactose } \\
\text { peptone } \\
\text { water }\end{array}$ & $\begin{array}{l}\text { Reaction, lactose-fer- } \\
\text { menting mutants } \\
\text { Reaction, lactose-fer- } \\
\text { menting mutants }\end{array}$ & $\begin{array}{l}- \\
-\end{array}$ & $\begin{array}{l}- \\
\text { Acid } \\
-\end{array}$ & $\overline{\text { Acid }}$ & $\begin{array}{l}\text { Acid } \\
+ \\
+ \\
+\end{array}$ \\
\hline
\end{tabular}

Inoculum: 20,000 cells.

that culture E.C. 8 behaved in a similar manner to that described by Lewis. An acid reaction was obtained after four days' incubation coinciding with the appearance of lactose-fermenting mutant cells. In $5 \%$ lactose peptone water a more rapid fermentation reaction occurred, thus confirming the findings of Kriebel. However, fermentation did not appear to be dependent on the presence of detectable lactose-fermenting mutant cells, as such colonies did not appear on plating until two days after an acid reaction was obtained.
The study of colonies grown on lactose peptone agar gave a result similar to that found in the lactose liquid media. Lactose-fermenting papillae were observed in most colonies grown on $1 \%$ lactose peptone agar after four days' incubation. These papillae fermented $1 \%$ and $5 \%$ lactose peptone water within 24 hours. Colonies grown on $5 \%$ lactose peptone agar did not ferment lactose after 24 hours' incubation, but consistently showed good fermentation (whole colony red) after 48 hours' incubation. These red colonies when replated on to $5 \%$ lactose agar reverted to the original non-lactose-fermenting state, but after 48 hours' incubation were once again good fermenters. Lactose-fermenting papillae were observed in most of the colonies after three days' incubation, their deeper red colour distinguishing them from the colony itself. These papillae subsequently fermented $1 \%$ and $5 \%$ lactose peptone water within 24 hours.

It appears that the factors controlling fermentation of $1 \%$ and $5 \%$ lactose by culture E.C.8 differ considerably. Fermentation of $1 \%$ lactose depends on the slow development of sufficient lactose-fermenting mutant cells. Although lactose-fermenting mutants do arise in $5 \%$ lactose, the whole population appears to be capable of fermenting the lactose after 48 hours' incubation.

It seemed possible that the failure of the organism to ferment $5 \%$ lactose within 24 hours might be associated with some blocking effect produced by the peptone. Such a blocking effect, if present, ought to be reduced by lowering the concentration of the peptone. It was decided, therefore, to investigate the effects of growth in media containing varying amounts of peptone and lactose and to discover, if possible, a point at which rapid fermentation began.

\section{Fermentation Reactions of Culture E.C.8 in Liquid Media Containing Varying Amounts of Peptone and Lactose}

Procedure-Concentrations of peptone ranging from $0.1 \%$ to $1 \%$ in distilled water were prepared. Lactose in strengths of $1 \%$ to $5 \%$ was added to each concentration of peptone. Andrade's indicator was added to each batch of medium, and all media were tubed in $5 \mathrm{ml}$. amounts. Three drops $(0.06 \mathrm{ml}$.) of a heavy suspension of culture E.C.8 in distilled water representing approximately $10^{8}$ organisms were inoculated into $5 \mathrm{ml}$. of each medium. This heavy inoculum was used to counteract any slowing down of the growth rate which might occur in the media containing small amounts of peptone.

Results.-The results are shown in Table II. In the media containing high concentrations of 
TABLE II

FERMENTATION REACTIONS OF CULTURE E.C.8 IN LIQUID MEDIA CONTAINING VARYING AMOUNTS OF PEPTONE AND LACTOSE

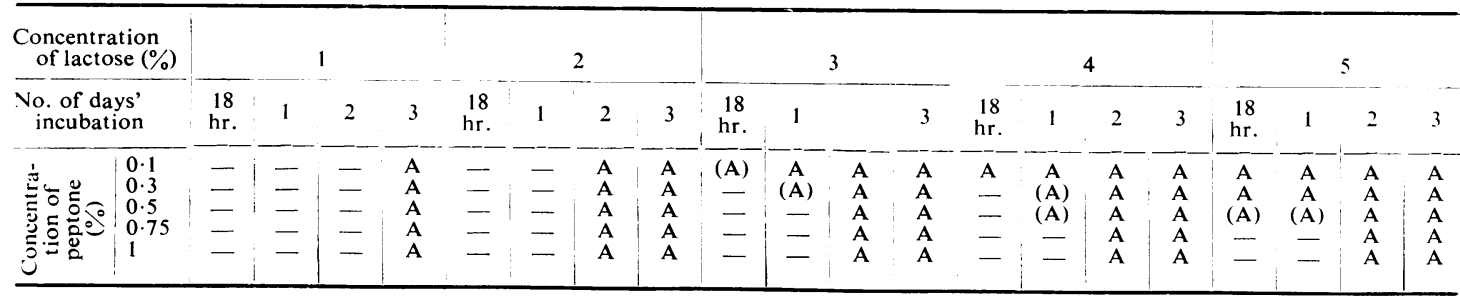

TABLE III

COMPARISON OF CULTURES OF VARIOUS ORGANISMS GROWN IN $1 \%$ LACTOSE PEPTONE WATER AND $5 \%$ LACTOSE $0.1 \%$ PEPTONE WATER

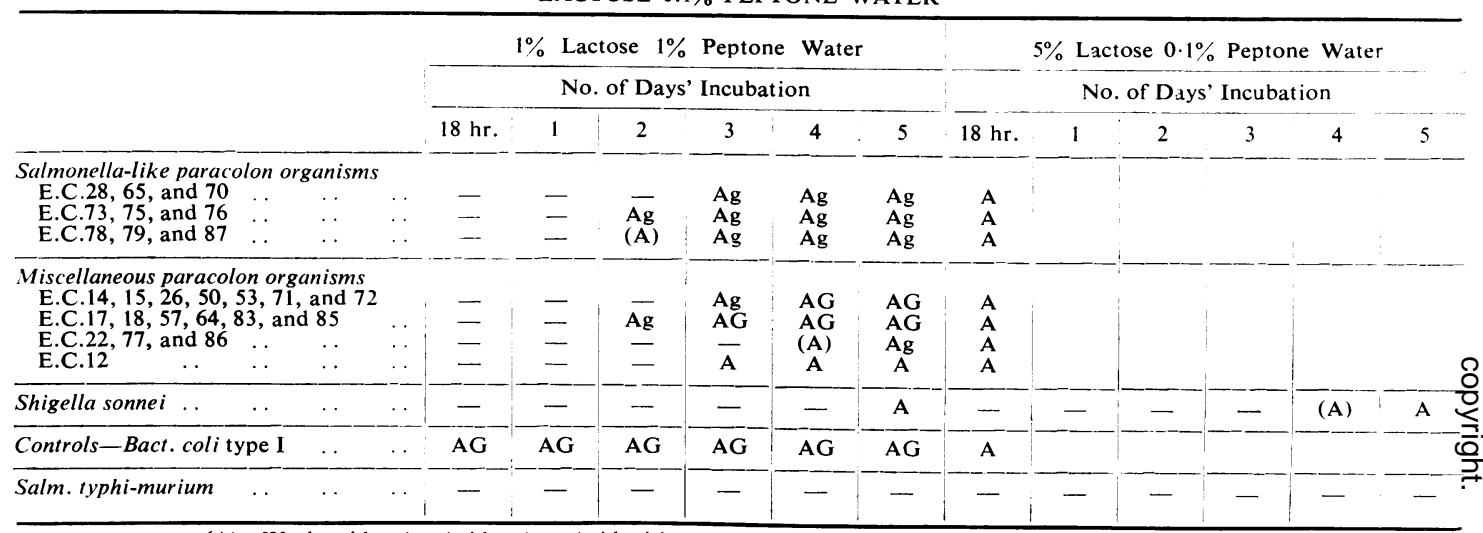

(A) $=$ Weak acid. $\quad \mathbf{A}=$ Acid. $\quad A g=$ Acid with small amount of gas. $\quad A G=$ Acid with large amount of gas

lactose and low concentrations of peptone an acid reaction was obtained within 18 hours. As the concentration of peptone was increased, fermentation of lactose was delayed. A duplicate series of tubes grown under anaerobic conditions gave similar results. No advantage was obtained by using low concentrations of peptone with $1 \%$ lactose. This is not surprising, since fermentation under these conditions has been shown to depend solely on the presence of sufficient lactosefermenting mutant cells. There is no clear line of demarcation between the two types of fermentation as found with $1 \%$ and $5 \%$ lactose. Fermentation is accelerated as the strength of lactose used is increased.

\section{Further Experiments}

It was decided to examine a number of similar strains of salmonella-like and other miscellaneous paracolon bacteria, to see whether results similar to those found with culture E.C.8 would be obtained. A strain of Shigella sonnei was also included in the series. Approximately $10^{8}$ organisms of each culture were inoculated into $5 \mathrm{ml}$. of $5 \%$ lactose $0.1 \%$ peptone water containing Andrade's indicator. A similar inoculum was added to $5 \mathrm{ml}$. of standard $1 \%$ lactose $1{ }^{\circ}$ peptone water containing Andrade's indicator and a Durham tube for the detection of gas.

A comparison of fermentation reactions obtained with both media is shown in Table III. All the salmonella-like paracolon organisms examined gave an acid reaction after 18 hours' incubation when grown in $5 \%$ lactose $0.1 \%$ peptone water, whereas in the standard $1 \%$ lactose peptone water at least 48 hours were required. All the miscellaneous cultures of late lactosefermenting paracolon bacteria investigated gave a similar result. The strain of Shigella sonnei showed considerably delayed fermentation in both media. This result is rather surprising since delayed fermentation of lactose by Shigella sonnei is in many respects similar to that found with the mutabile types (Cook, Knox, and Tomlinson. 1951).

It will be noted that in these experiments, as in those already described, the criterion used in the special media was an acid reaction without any question of gas production. Experiments not tabulated had already shown that in such media 
the paracolon organisms produced no gas at all, and Bact. coli type I yielded after 24 hours only a minute bubble which did not increase on further incubation. The reason for this has already been suggested by Pinsky and Stokes (1952), who showed that gas production could be expected only in relatively complex media providing adequate supplies of amino-acids and energy sources. It is probable that the $0.1 \%$ peptone medium is deficient in both these respects.

\section{Proposed Medium}

In view of these results it is recommended that a medium containing $5 \%$ lactose and $0.1 \%$ peptone should be included in the routine biochemical tests used for the investigation of possible salmonellae. Such a medium has been used in this laboratory for several months and has given excellent results in rapidly distinguishing between salmonella-like paracolon organisms and true salmonellae.

Preparation of Medium.-The following are the materials and method used :

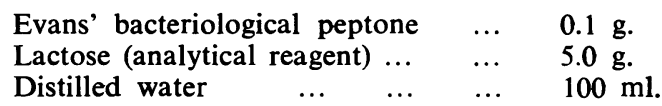

The $p \mathrm{H}$ is adjusted to 7.2 and $1 \mathrm{ml}$. of Andrade's indicator added, and the medium sterilized by Seitz filtration.* The final medium should be pale pink. The medium should be put up in tubes or bottles aseptically in $5 \mathrm{ml}$. amounts. To check for sterility, the medium should be incubated at $37^{\circ} \mathrm{C}$. for 48 hours. It is essential that sterilization should be effected by filtration and not by heat, as it has been found that $5 \%$ lactose is readily broken down during autoclaving or steaming.

Owing to the low nutrient content of the medium it is important that a large inoculum should be used. An acid reaction is indicated by a progressive change

*Before filtration it is advisable to pass a small volume of $1 \%$ Andrade's indicator in distilled water through the filter to counteract absorption of the indicator by the filter pad. from a pale pink to an intense red. With salmonellae and other non-lactose-fermenting organisms the medium changes from a pale pink to a colourless solution.

\section{Summary}

A simple medium has been described which will enable late lactose-fermenting organisms of the paracolon group to ferment lactose rapidly.

This medium has proved to be particularly useful for the rapid elimination of salmonella-like paracolon bacteria which ferment $1 \%$ lactose peptone water slowly. It is recommended that this medium should be included in the routine biochemical tests used for the investigation of possible salmonellae.

The results obtained suggest that there is a difference between the factors controlling fermentation of $1 \%$ and of $5 \%$ lactose. Fermentation of $1 \%$ lactose peptone water by a late lactosefermenting paracolon organism proceeded in the orthodox manner; fermentation coincided with the appearance of lactose-fermenting mutant cells. Fermentation of $5 \%$ lactose peptone water did not appear to be dependent on the presence of lactosefermenting mutant cells. Although mutant cells appeared after prolonged incubation, the whole population rapidly fermented $5 \%$ lactose provided the concentration of peptone was reduced. Further studies are being made of these fermentative differences and of the apparent blocking effect found with peptone.

Our grateful thanks are due to Dr. R. D. Gray, Dr. W. H. H. Jebb, and Dr. A. H. Tomlinson for much helpful advice and criticism.

\section{REFERENCES}

Chilton, Martha L., and Fulton, MacD. (1946). J. Lab. clin. Med., 31, 824.

Cook, G. T., Knox, R., and Tomlinson, A. H. (1951). J. exp. Path., 32, 203.

Kriebel, Ruth M. (1934). J. Bact., 27, 357.

Lewis, I. M. (1934). Ibid., 28, 619.

Massini, R.(1907). Arch.Hyg. (Berl.), 61, 250.

Pinsky, M. J., and Stokes, J. L. (1952). J. Bact., 64, 151. 